\title{
Fatores de risco para a ocorrência de anticorpos contra Toxoplasma gondii e Neospora caninum em cães domiciliados no Nordeste do Brasil $^{1}$
}

\section{Risk factors associated with the occurrence of antibodies against Toxoplasma gondii and Neospora caninum in domiciled dogs in Northeastern Brazil}

\author{
Sabrina Barros Araujo Dantas²; Annielle Regina da Fonsêca Fernandes²; \\ Orestes Luiz de Souza Neto ${ }^{3}$; Rinaldo Aparecido Mota ${ }^{4}$; Clebert José Alves ${ }^{5}$; \\ Sérgio Santos de Azevedo ${ }^{5 *}$
}

\section{Resumo}

O objetivo do trabalho foi determinar a ocorrência de anticorpos contra Toxoplasma gondii e Neospora caninum, e determinar os fatores de risco associados à soropositividade em cães domiciliados no município de Patos, Estado da Paraíba. Foram colhidas amostras de sangue de 173 cães atendidos no Hospital Veterinário da Universidade Federal de Campina Grande (HV/UFCG), Campus de Patos, Paraíba, no período de fevereiro a outubro de 2011. Para o diagnóstico sorológico das infecções por T. gondii e $N$. caninum foi utilizada a reação de imunofluorescência indireta (RIFI), adotando-se como pontos de corte as diluições 1:64 (T. gondii) e 1:50 (N. caninum). Dos 173 cães utilizados, 27 (15,6\%) foram soropositivos para T. gondii, e $13(7,5 \%)$ para $N$. caninum. As variáveis idade de 13 a 48 meses $(\mathrm{OR}=3,90)$, idade $>48$ meses $(\mathrm{OR}=5,14)$ e cães sem raça definida $(\mathrm{OR}=3,12)$ foram identificadas como fatores de risco associados à soropositividade para T. gondii, e para $N$. caninum, a variável acesso dos cães a açudes $(\mathrm{OR}=5,67)$ foi identificada como fator de risco. As infecções por $T$. gondii e $N$. caninum, detectadas pela RIFI, estão presentes em cães domiciliados no município de Patos, PB, bem como se recomenda, com base na análise de fatores de risco, evitar o acesso dos animais a açudes.

Palavras-chave: Toxoplasmose canina, neosporose canina, RIFI, epidemiologia, controle

\begin{abstract}
The aim of this survey was to determine the occurrence of antibodies against Toxoplasma gondii and Neospora caninum and to determine the risk factors associated with seropositivity in domiciled dogs in the county of Patos, Paraíba state, Northeastern Brazil. One hundred seventy-three blood samples were collected from dogs attended at the Veterinary Hospital of the Federal University of Campina Grande (HV/UFCG), Campus of Patos, Paraíba, during February to October 2011. For the serological diagnosis
\end{abstract}

\footnotetext{
${ }^{1}$ Parte da Dissertação de Mestrado do primeiro autor.

${ }^{2}$ Discentes do Programa de Pós-Graduação em Medicina Veterinária, Centro de Saúde e Tecnologia Rural, Universidade Federal de Campina Grande, UFCG, Patos, PB. E-mail: sabrina_vet@yahoo.com.br; anni.regina@gmail.com

${ }^{3}$ Discente do Programa de Pós-Graduação em Ciência Veterinária, Universidade Federal Rural de Pernambuco, UFRPE, Recife, PE. E-mail: oresteshi@hotmail.com

${ }^{4}$ Prof. do Programa de Pós-Graduação em Ciência Veterinária, UFRPE, Recife, PE. E-mail: rinaldo.mota@hotmail.com

${ }^{5}$ Profs. do Programa de Pós-Graduação em Medicina Veterinária, Centro de Saúde e Tecnologia Rural, UFCG, PB. E-mail: ssazevedo@cstr.ufcg.edu.br; clebertja@uol.com.br

* Autor para correspondência
} 
of $T$. gondii and $N$. caninum infection the indirect fluorescent antibody test (IFAT) was used adopting as cut-off points the dilutions 1:64 (T. gondii) and 1:50 (N. caninum). Of the 173 dogs used $27(15.6 \%)$ were seropositive for T. gondii, and 13 (7.5\%) for $N$. caninum. Variables age from 13 to 48 months (OR $=3.90)$, age $>48$ months $(\mathrm{OR}=5.14)$ and mixed-breed dogs $(\mathrm{OR}=3.12)$ were identified as risk factors associated with $T$. gondii seropositivity, and for $N$. caninum the variable access of the dogs to ponds $(\mathrm{OR}=5.67)$ was identified as risk factor. $T$. gondii and $N$. caninum infections, detected by IFAT, are present in domiciled dogs in the county of Patos, PB, as well as based on the risk factor analysis it is recommended to avoid the access of dogs to ponds.

Key words: Canine toxoplasmosis, canine neosporosis, IFAT, epidemiology, control

\section{Introdução}

Os protozoários Toxoplasma gondii e Neospora caninum possuem ampla distribuição geográfica, são parasitas intracelulares obrigatórios e membros do filo Apicomplexa. O ciclo biológico desses protozoários é heteroxênico, possuindo carnívoros como hospedeiros definitivos. Na toxoplasmose os felídeos exercem esse papel, enquanto que na neosporose são representados pelos cães e algumas espécies de canídeos silvestres (DUBEY, 2010; GUIMARÃES, 2011).

Para ambos os agentes várias espécies podem atuar como hospedeiros intermediários, contudo, na infecção por $N$. caninum os bovinos merecem destaque pelos danos reprodutivos e produtivos que o agente ocasiona (REICHEL et al., 2013). A toxoplasmose é um sério problema de saúde pública, uma vez que a doença clinica importante ocorre em grupos de risco, formados principalmente por mulheres grávidas e indivíduos imunocomprometidos (TENTER; HECKEROTH; WEISS, 2000). Os seres humanos adquirem a infecção principalmente pelo consumo de carne crua ou mal cozida de animais de produção, especialmente suínos, caprinos e ovinos (DUBEY, 2010).

Os cães desempenham papel primordial no ciclo biológico do $N$. caninum e, embora essa espécie não seja apontada como hospedeiro definitivo para o T. gondii, Lindsay et al. (1997) comprovaram sua importância como veiculador mecânico desse protozoário, atuando como sentinelas para a infecção. Sendo assim, os cães podem ser considerados um elo importante na cadeia epidemiológica da neosporose e da toxoplasmose, o que justifica o crescente interesse em tentar definir o papel desses animais como fontes de infecção para outras espécies, auxiliando na escolha de medidas que interfiram no ciclo natural dos agentes (ULLMANN et al., 2008; BLOS, 2009).

Objetivou-se determinar a frequência de anticorpos contra T. gondii e N. caninum, bem como identificar os fatores de risco em cães domiciliados atendidos na rotina do Hospital Veterinário da Universidade Federal de Campina Grande (HV/ UFCG), Campus de Patos, PB.

\section{Material e Métodos}

A pesquisa foi realizada em Patos, município localizado no sertão da Paraíba. Foram colhidas 173 amostras de soro de cães domiciliados de ambos os sexos, de raças variadas e com idade acima de três meses, que foram atendidos no Hospital Veterinário da Universidade Federal de Campina Grande (HV/ UFCG), Campus de Patos, no período de fevereiro a outubro de 2011. A seleção dos cães foi realizada de acordo com a autorização do proprietário, além da condição corporal na qual os animais se encontravam no momento da consulta.

As colheitas de sangue foram efetuadas por venopunção cefálica ou jugular externa, utilizandose seringas descartáveis de $5 \mathrm{~mL}$, com posterior obtenção do soro e estocagem a $-20^{\circ} \mathrm{C}$ até a realização da sorologia. O proprietário que autorizou a participação do seu cão na pesquisa respondeu 
a um questionário epidemiológico que continha informações sobre possíveis fatores de risco associados à exposição aos agentes. As informações foram inseridas em banco de dados elaborado com o programa Microsoft Access ${ }^{\circledR}$.

A detecção de anticorpos contra $T$. gondii foi realizada com a reação de imunofluorescência indireta (RIFI), segundo metodologia descrita por Camargo (1974). Lâminas sensibilizadas com taquizoítos da cepa $\mathrm{RH}$, mantida em camundongos foram utilizadas. Para a detecção de anticorpos contra $N$. caninum também foi utilizada a RIFI, segundo Dubey et al. (1988), empregando-se lâminas sensibilizadas com a cepa NC-1, obtida a partir do cultivo de células vero. Os soros para ambos os agentes foram diluídos em solução salina tamponada ( $\mathrm{pH} 7,2)$, adotando-se como ponto de corte as diluições 1:64 para $T$. gondii e 1:50 para $N$. caninum. Para a visualização da reação foi utilizado o conjugado comercial contra IgG canino (Sigma, USA) marcado com isotiocianato de fluoresceína. As amostras que apresentaram taquizoítos com fluorescência periférica total foram consideradas positivas e submetidas a diluições sucessivas, adotando-se como título final o correspondente a última diluição com reação positiva.

Os dados obtidos com os questionários epidemiológicos foram analisados estatisticamente em duas etapas, análise univariável e análise multivariável, para a determinação dos possíveis fatores de risco associados à soropositividade para $T$. gondii e $N$. caninum. Na análise univariável, foram formados dois grupos de animais - soropositivos e soronegativos - que foram comparados frente às variáveis analisadas. Aquelas variáveis que apresentaram valor de $P \leq 0,2$ pelo teste de quiquadrado ou teste exato de Fisher foram selecionadas para a análise multivariável, utilizando-se regressão logística múltipla (HOSMER; LEMESHOW, 2000). O nível de significância adotado foi de 5\%, e as análises foram realizadas com o programa SPSS 20.0 for Windows.

\section{Resultados e Discussão}

Dos 173 animais testados 27 (15,6\%) foram soropositivos para T. gondii. Com relação à distribuição da titulação de anticorpos, cinco $(18,5 \%)$, seis $(22,2 \%)$, sete $(25,9 \%)$, sete $(25,9 \%)$ e dois $(7,4 \%)$ animais apresentaram títulos 64 , 128, 256, 512 e 1024, respectivamente. Embora a frequência obtida nesse estudo seja baixa quando comparada a de outros estados brasileiros como Mato Grosso, 88,5\% (SANTOS et al., 2009) e Pernambuco, 57,6\% (FIGUEREDO et al., 2008), nota-se um alto percentual de soropositivos com titulações consideradas elevadas. Dados da literatura divergem quanto à dinâmica de anticorpos na toxoplasmose ativa e crônica para a espécie canina, contudo para outras espécies esse parâmetro já foi estabelecido. Dubey e Kirkbride (1989) afirmaram que em ovinos títulos $\geq 1024$ indicam infecção ativa, enquanto que títulos $<1024$ são sugestivos de infecção crônica.

Para N. caninum obteve-se 13 (7,5\%) animais soropositivos, sendo três $(23,1 \%)$, quatro $(30,8 \%)$, cinco $(38,5 \%)$ e um $(7,7 \%)$ animais soropositivos com títulos 50, 100, 200 e 400, respectivamente. Dados de prevalência relatados em outros países demonstram uma ampla variação, desde 0,5\% na Suécia (BJÖRKMAN; LAUDEN; UGGLA, 1994) até 30,7\% na Nova Zelândia (ANTONY; WILLIAMSON, 2003). No Brasil foram descritas soropositividades variando de $1,98 \%$ em São Paulo (COIRO et al., 2011) até 45\% no Maranhão (TEIXEIRA et al., 2006).

As diferenças nas frequências de soropositividade encontradas no presente trabalho com as observadas em outros estudos podem ser decorrentes de vários fatores, como tamanho amostral, teste diagnóstico utilizado, período de realização do estudo e características individuais da população canina estudada (CAÑÓN-FRANCO et al., 2003; AZEVEDO et al., 2005). Aliado a isso, todos os animais amostrados foram incluídos no estudo durante atendimento ambulatorial, característica 
que reflete maior cuidado dos proprietários com os animais, o que poderia justificar a baixa frequência de soropositividade tanto para $T$. gondii quanto para N. caninum.

Para o T. gondii, na análise de fatores de risco, foram selecionadas na análise univariável $(P \leq 0,2)$ as variáveis idade, raça, ambiente onde o animal vive e acesso a açudes (Tabela 1). Na regressão logística as variáveis idade de 13 a 48 meses (OR = $3,90)$, idade $>48$ meses $(\mathrm{OR}=5,14)$ e animais sem raça definida $(\mathrm{OR}=3,12)$ foram identificadas como fatores de risco (Tabela 2).

Ao considerar a idade dos animais como fator de risco nota-se que animais com idade de 13 a 48 meses possuem 3,90 e os com idade $>48$ meses 5,14 vezes mais chance de serem soropositivos para $T$. gondii, demonstrando um risco crescente com o aumento da idade do animal. Esses resultados corroboram os descritos por Cañón-Franco et al. (2004) e Azevedo et al. (2005), que obtiveram associação entre a soropositividade e a idade adulta do animal. Notase que a infecção pós-natal é uma das principais formas de transmissão da toxoplasmose, assumindo importância, em função da idade, para os animais adultos, que podem entrar em contato com fontes de infecção e as mais variadas vias de transmissão disseminadas no meio ambiente.

Cães sem raça definida possuem 3,12 vezes mais chance de serem soropositivos para $T$. gondii, resultado que corrobora os descritos por Moura et al. (2009) e Carlos et al. (2010), contudo diverge dos descritos por Bresciani et al. (2007) que não encontraram associação entre o padrão racial e a presença de anticorpos para o referido protozoário. Essa variável pode estar estritamente associada a outros fatores como manejo a que o animal é submetido e características dos proprietários, haja vista que na maioria das vezes cães sem padrão racial são adquiridos por proprietários com menor poder econômico e são submetidos a condições de manejo inadequadas, assim como uma dieta insuficiente ou inadequada, e muitos desses animais possuem acesso irrestrito ao ambiente externo de seus domicílios, o que permite o contato com diferentes ambientes, predispondo à exposição ao agente.

$\mathrm{Na}$ análise univariável dos fatores de risco para $N$. caninum, as variáveis sexo, tipo de criação, contato com bovinos, ambiente onde o animal vive e acesso a açudes foram associadas $(P \leq 0,2)$ e selecionadas para a análise multivariável (Tabela 1), pela qual apenas a variável acesso a açudes $(\mathrm{OR}=$ 5,67 ) foi identificada como fator de risco (Tabela 2).

Os cães que possuem acesso a açudes apresentam 5,67 vezes mais chances de serem soropositivos para $N$. caninum. Esse achado pode ser justificado pela maior predisposição à infecção pelo acesso irrestrito dos mesmos ao meio ambiente, assim como pelas condições de umidade e temperatura do solo em áreas alagadiças ou próximas a açudes, o que pode favorecer a permanência e a viabilidade dos oocistos por períodos mais prolongados (CAÑÓN-FRANCO et al., 2004; MOURA et al., 2009; GUIMARÃES, 2011). 
Tabela 1. Análise univariável dos fatores de risco associados à soropositividade para T. gondii e N. caninum em 173 cães do município de Patos, PB, no período de fevereiro a outubro de 2011.

\begin{tabular}{|c|c|c|c|c|c|}
\hline \multirow[t]{2}{*}{ Variável/Categoria } & \multirow{2}{*}{$\begin{array}{l}\text { Número total de } \\
\text { animais }\end{array}$} & \multicolumn{2}{|c|}{$\begin{array}{c}\text { Soropositividade para Toxoplasma } \\
\text { gondii }\end{array}$} & \multicolumn{2}{|c|}{$\begin{array}{c}\text { Soropositividade para Neospora } \\
\text { caninum }\end{array}$} \\
\hline & & $\mathrm{N}^{0}$ soropositivos & $P$ & $\mathrm{~N}^{\mathbf{0}}$ soropositivos & $P$ \\
\hline \multicolumn{6}{|l|}{ Sexo } \\
\hline Macho & 97 & $15(15,5)$ & & $10(10,3)$ & \\
\hline Fêmea & 76 & $12(15,8)$ & 1,000 & $3(3,9)$ & $0,199 *$ \\
\hline \multicolumn{6}{|l|}{ Idade } \\
\hline 3-12 meses & 53 & $3(5,7)$ & & $4(7,5)$ & \\
\hline 13 - 48 meses & 65 & $12(18,5)$ & & $4(6,2)$ & \\
\hline$>48$ meses & 55 & $12(21,8)$ & $0,050^{*}$ & $5(9,1)$ & 0,831 \\
\hline \multicolumn{6}{|l|}{ Raça } \\
\hline Sem raça definida & 101 & $21(20,8)$ & & $6(5,9)$ & \\
\hline Com raça definida & 72 & $6(8,3)$ & $0,044^{*}$ & $7(9,7)$ & 0,524 \\
\hline \multicolumn{6}{|l|}{ Tipo de criação } \\
\hline Domiciliar & 123 & $18(14,6)$ & & $11(8,9)$ & \\
\hline Semidomiciliar & 33 & $7(21,2)$ & & $0(0)$ & \\
\hline Solto & 17 & $2(11,8)$ & 0,587 & $2(11,8)$ & $0,175^{*}$ \\
\hline \multicolumn{6}{|l|}{ Alimentação } \\
\hline Ração comercial & 34 & $3(8,8)$ & & $2(5,9)$ & \\
\hline Alimento caseiro & 23 & $5(21,7)$ & & $2(8,7)$ & \\
\hline Ambos & 116 & $19(16,4)$ & 0,387 & $9(7,8)$ & 0,911 \\
\hline \multicolumn{6}{|l|}{ Contato com cães } \\
\hline Não & 81 & $13(16)$ & & $6(7,4)$ & \\
\hline Sim & 92 & $14(15,2)$ & 1,000 & $7(7,6)$ & 1,000 \\
\hline \multicolumn{6}{|l|}{ Contato com bovinos } \\
\hline Não & 171 & $26(15,2)$ & & $12(7)$ & \\
\hline Sim & 2 & $1(50)$ & 0,289 & $1(50)$ & $0,145^{*}$ \\
\hline \multicolumn{6}{|l|}{ Contato com gatos } \\
\hline Não & 143 & $22(15,4)$ & & $8(5,6)$ & \\
\hline Sim & 30 & $5(16,7)$ & 0,788 & $5(16,7)$ & 0,327 \\
\hline \multicolumn{6}{|l|}{ Ambiente onde o cão vive } \\
\hline Terra & 58 & $13(22,4)$ & & $3(5,2)$ & \\
\hline Cimento & 75 & $8(10,7)$ & & $4(5,3)$ & \\
\hline Ambos & 40 & $6(15)$ & $0,179^{*}$ & $10(15)$ & $0,123^{*}$ \\
\hline \multicolumn{6}{|c|}{$\begin{array}{l}\text { Realiza limpeza do ambiente } \\
\text { onde o cão vive }\end{array}$} \\
\hline Não & 15 & $2(13,3)$ & & $1(6,7)$ & \\
\hline Sim & 158 & $25(15,8)$ & 1,000 & $12(7,6)$ & 1,000 \\
\hline \multicolumn{6}{|l|}{ Passeia com o cão } \\
\hline Não & 63 & $11(17,5)$ & & $5(7,9)$ & \\
\hline Sim & 110 & $16(14,5)$ & 0,771 & $8(7,3)$ & 1,000 \\
\hline \multicolumn{6}{|l|}{ Viaja com o cão } \\
\hline Não & 150 & $24(16)$ & & $12(8)$ & \\
\hline Sim & 23 & $3(13)$ & 1,000 & $1(4,3)$ & 1,000 \\
\hline \multicolumn{6}{|l|}{ Presença de ratos } \\
\hline Não & 98 & $16(16,3)$ & & $5(5,1)$ & \\
\hline $\operatorname{Sim}$ & 75 & $11(14,7)$ & 0,931 & $8(10,7)$ & 0,278 \\
\hline \multicolumn{6}{|l|}{ Acesso a açudes } \\
\hline Não & 146 & $20(13,7)$ & & $7(4,8)$ & \\
\hline Sim & 27 & $7(25,9)$ & $0,145^{*}$ & $6(22,2)$ & $0,007^{*}$ \\
\hline
\end{tabular}

* Variáveis selecionadas para a regressão logística múltipla $(P \leq 0,2)$.

Fonte: Elaboração dos autores. 
Tabela 2. Fatores de risco associados com a soropositividade para $T$. gondii e $N$. caninum em 173 cães domiciliados no município de Patos, PB, no período de fevereiro a outubro de 2011.

\begin{tabular}{lccc}
\hline Fator de risco & Odds ratio (OR) & IC (95\%) & $P$ \\
\hline Soropositividade para Toxoplasma gondii & & & \\
$\quad$ Idade de 13 a 48 meses & 3,90 & $1,03-14,94$ & 0,046 \\
Idade > 48 meses & 5,14 & $1,33-19,79$ & 0,017 \\
$\quad$ Cães sem raça definida & 3,12 & $1,17-8,34$ & 0,023 \\
Soropositividade para Neospora caninum & & & \\
$\quad$ Acesso do cão a açudes & 5,67 & $1,73-18,52$ & 0,004 \\
\hline
\end{tabular}

Fonte: Elaboração dos autores.

\section{Conclusões}

As infecções por T. gondii e $N$. caninum, detectadas pela RIFI, estão presentes em cães domiciliados atendidos do município de Patos, Estado da Paraíba. Com base na análise de fatores de risco, recomenda-se evitar o acesso dos cães a áreas alagadas ou próximas a açudes, tendo em vista que as características ambientais dessas áreas favorecem a maior permanência e viabilidade dos oocistos, o que pode aumentar os riscos de infecção.

\section{Agradecimentos}

Ao Prof. Dr. Luis Fernando Pita Gondim, da Universidade Federal da Bahia (UFBA), pelo fornecimento da cepa de $N$. caninum utilizada na sorologia. À Coordenação de Aperfeiçoamento de Pessoal de Nível Superior (CAPES) pela concessão de bolsa de mestrado ao primeiro autor.

\section{Referências}

ANTONY, A.; WILliAMSON, N. B. Prevalence of antibodies to Neospora caninum in dogs of rural or urban origin in central New Zealand. New Zealand Veterinary Journal, Palmerston North, v. 51, n. 5, p. 232-237, 2003.

AZEVEDO, S.S.;BATISTA, C.S.A.; VASCONCELLOS, S. A.; AGUIAR, D. M.; RAGOZO, A. M. A.; RODRIGUES, A. A. R.; ALVES, C. J.; GENNARI, S. M. Seroepidemiology of Toxoplasma gondii and Neospora caninum in dogs from the state of Paraiba, Northeast region of Brazil. Research in Veterinary Science, Oxford, v. 79, n. 1, p. 51-56, 2005.
BJÖRKMAN, C.; LAUDEN, A.; UGGLA, A. Prevalence to antibodies to Neospora caninum and Toxoplasma gondii in Swedish dogs. Acta Veterinaria Scandinavica, London, v. 35, n. 4, p. 445-447, 1994.

BLOS, B. Ocorrência de anticorpos para Neospora caninum e Toxoplasma gondii em seres humanos e sua relação com a posse de animais de estimação. 2009. Monografia (Graduação em Biomedicina) - Instituto de Ciências Básicas da Saúde. Universidade Federal do Rio Grande do Sul.

BRESCIANI, K. D. S.; COSTA, A. J.; NUNES, C. M.; SERRANO, A. C. M.; MOURA, A. B.; STOBBE, N. S.; PERRI, S. H. V.; DIAS, R. A.; GENNARI, S. M. Ocorrência de anticorpos contra Neospora caninum e Toxoplasma gondii e estudo de fatores de risco em cães de Aracatuba-SP. Ars Veterinaria, Jaboticabal, v. 23, n. 1, p. 40-46, 2007.

CAMARGO, M. E. Introdução às técnicas de imunofluorescência. Revista Brasileira de Patologia Clínica, São Paulo, v. 10, n. 3, p. 143-171, 1974.

CAÑÓN-FRANCO, W. A.; BERGAMASCHI, D. P.; LABRUNA, M. B.; CAMARGO, L. M. A.; SOUZA, S. L. P.; SILVA, J. C. R.; PINTER, A.; DUBEY, J. P.; GENNARI, S. M. Prevalence of antibodies to Neospora caninum in dogs from Amazon, Brazil. Veterinary Parasitology, Amsterdam, v. 115, n. 1, p. 71-74, 2003.

CAÑÓN-FRANCO, W. A.; BERGAMASCHI, D. P.; LABRUNA, M. B.; CAMARGO, L. M. A.; SILVA, J. C. R.; PINTER, A.; GENNARI, S. M. Occurrence of antiToxoplasma gondii antibodies in dogs in the urban area of Monte Negro, Rondônia, Brazil. Veterinary Research Communications, Philadelphia, v. 28, n. 2, p. 113-118, 2004.

CARLOS, R. S. A.;ALBUQUERQUE, G. R.; BEZERRA, R. A.; SICUPIRA, P. M. L.; MUNHOZ, A. D.; LOPES, C. W. G. Ocorrência de anticorpos anti-Toxoplasma gondii e principais fatores de risco associados à infecção canina 
na região de Ilhéus-Itabuna, Estado da Bahia. Revista Brasileira de Medicina Veterinária, Rio de Janeiro, v. 32, n. 2, p. 115-121, 2010.

COIRO, C. J.; LANGONI, H.; SILVA, R. C.; ULLMANN, L. S. Fatores de risco para leptospirose, leishmaniose, neosporose e toxoplasmose em cães domiciliados e peridomiciliados em Botucatu-SP. Veterinária e Zootecnia, Botucatu, v. 18, n. 3, p. 393-407, 2011.

DUBEY, J. P. Toxoplasmosis of animals and humans. 2. ed. Boca Raton: CRC Press, 2010. 313 p.

DUBEY, J. P.; HATTEL, A. L.; LINDSAY, D. S.; TOPPER, M. J. Neonatal Neospora caninum infection in dogs: isolation of the causative agent and experimental transmission. Journal of the American Veterinary Medical Association, New York, v. 192, n. 10, p. 12591263, 1988.

DUBEY, J. P.; KIRBRIDE, C. A. Economic and public health considerations of congenital toxoplasmosis in lambs. Journal of the American Veterinary Medical Association, New York, v. 195, n. 12, p. 1715-1716, 1989.

FIGUEREDO, L. A.; DANTAS-TORRES, F.; FARIA, E. B.; GONDIM, L. P.; SIMÕES-MATTOS, L.; BRANDÃO-FILHO, S. P.; MOTA, R. A. Occurrence of antibodies to Neospora caninum and Toxoplasma gondii in dogs from Pernambuco, Northeast Brazil. Veterinary Parasitology, Amsterdam, v. 157, n. 1-2, p. 9-13, 2008.

GUIMARÃES, M. S. Ciclo Silvestre de Neospora caninum e sua importância na epidemiologia para os animais domésticos. 2011. Tese (Doutorado em Ciência Animal) - Universidade Federal de Goiás, Goiânia.

HOSMER, D. W.; LEMESHOW, S. Applied logistic regression. New York: John Wiley \& Sons, 2000. 375 p.

LINDSAY, D. S.; DUBEY, J. P.; BUTLER, J. M.; BLAGBURN, B. L. Mechanical transmission of Toxoplasma gondii oocysts by dogs. Veterinary Parasitology, Amsterdam, v. 73, n. 1-2, p. 27-33, 1997.
MOURA, A. B.; SOUZA, A. P.; SARTOR, A. A.; BELLATO, V.; TEIXEIRA, E. B.; PISETTA, G. M.; HEUSSER JÚNIOR, A. Ocorrência de anticorpos e fatores de risco para infecção por Toxoplasma gondii em cães, nas cidades de Lages e Balneário Camboriú, Santa Catarina, Brasil. Revista Brasileira de Parasitologia Veterinária, São Carlos, v. 18, n. 3, p. 52-56, 2009.

REICHEL, M. P.; AYANEQUI-ALCÉRRECA, M. A.; GONDIM, L. F. P.; ELLIS, J. T. What is the global economic impacto of Neospora caninum in cattle the billion dollar question. International Journal for Parasitology, Oxford, v. 43, n. 2, p. 133-142, 2013.

SANTOS, T. R.; COSTA, A. J.; TONIOLLO, G. H.; LUVIZOTTO, M. C.; BENETTI, A. H.; SANTOS, R. R.; MATTA, D. H.; LOPES, W. D. Z.;OLIVEIRA, J. A.; OLIVEIRA, G. P. Prevalence of anti-Toxoplasma gondii antibodies in dairy cattle, dogs, and humans from the Jauru micro-region, Mato Grosso state, Brazil. Veterinary Parasitology, Amsterdam, v. 161, n. 3-4, p. 324-326, 2009.

TEIXEIRA, W. C.; SILVA, M. I. S.; PEREIRA, J. G.; PINHEIRO, A. M.; ALMEIDA, M. A. O.; GONDIM, L. F. P. Frequência de cães reagentes para Neospora caninum em São Luiz, Maranhão. Arquivo Brasileiro de Medicina Veterinária e Zootecnia, Belo Horizonte, v. 58, n. 4, p. 685-687, 2006.

TENTER, A. M.; HECKEROTH, A. R.; WEISS, L. M. Toxoplasma gondii: from animals to human. International Journal for Parasitology, Oxford, v. 30, n. 12-13, p. 1217-1258, 2000.

ULLMANN, L. S.; GUIMARÃES, F. F.; FORNAZARI, F.; TOMÉ, R. O.; CAMOSSI, L. G.; GRECA, H.; SILVA, R. C.; MENOZZI, B. D.; LANGONI, H. Ações de vigilância continuada, papel do cão como sentinela para toxoplasmose. Revista Brasileira de Parasitologia Veterinária, São Carlos, v. 17, n. 1, p. 345-347, 2008. 
